\title{
The Importance of Physical Environment for Guest Satisfaction on Restaurant in Bali
}

\author{
I Gusti Ayu Dewi Hendriyani \\ Sekolah Tinggi Pariwisata Nusa Dua Bali, Indonesia \\ Email: dewi.hendriyani2@gmail.com
}

\begin{abstract}
The physical environment of a restaurant today, prioritized as one of the attractions of a restaurant for its customers. Customer satisfaction is the goal of all businesses including restaurants. Customer satisfaction is a dynamic condition associated with fulfilling customer expectations of the service experience that has been provided. In the field of tourism especially providers of products and services such as restaurants, satisfied customers can cause customers to come back to the restaurant. The purpose of this study is to determine the factors and variables that can satisfy customers in restaurants in Bali. The study sites are located in $\mathbf{1 0}$ locations at 22 new restaurants in Bali. The method of this research is quantitative method with confirmatory factor analysis with 105 respondents. The observed factors consist of 6 factors with 21 variables that are 1) facility aesthetic factor (5 variables), 2). Ambience factor (4 variables), 3). Lighting factor (3 variables), 4). Atmosphere factor (4 variables), 5). Guest table setup factors (3 variables) and 6). Employee service factor ( 2 variables). The results of research on the role of the physical environment on customer satisfaction in restaurants in Bali as a whole is in good condition. The most determining factor of customer satisfaction is the atmosphere factor (F2) followed by the facility's aesthetic factor (F1). While the variable that most determine customer satisfaction is variable X6 (comfortable room temperature) followed by variable X1 (clean furniture). Strategic implementation for the restaurant based on the results of this study is that the manager can improve factors and variables that have been good and improve factors and variables that have not been good.
\end{abstract}

\section{Keywords—Physical Environment, Guest Satisfaction, Restaurant}

\section{INTRODUCTION}

There are many factors that affect whether a restaurant will be profitable in its business or not. These factors include the menu offered, the cost of food, other variable costs, marketing efforts, management of management, human resource management and more. On the other hand there are things that are often overlooked as factors that contribute to long-term profitability of the atmosphere of the restaurant itself. Research has shown, the atmosphere can affect everything from customer perceptions to a restaurant related to the value of reliability and responsiveness. Customers can decide to go back to a restaurant not depending on how much and how fast customers eat, how much they spend on food, and how long they stay in the restaurant. Restaurant owners, can set the restaurant's atmosphere appropriately, so customers will feel comfortable and enjoy their experience in the restaurant. When the customer is satisfied, and will become a loyal customer as a regular customer then of course will provide benefits for the restaurant (Tusukan:2016)

In Bali, there are many new restaurants that provide food and beverage services for their customers. Restaurant customers in Bali are not only foreign tourists, domestic tourists but also local Balinese themselves who want to try to eat outdoors on a regular basis every month. Very high business competition, causing the owners and managers of restaurants require a high strategy in order to survive in business competition in the long term and can provide services for all visitors. Information from Trip Advisor 2017, from some food blogger, social media and field survey in get there are 22 new restaurant in Bali which often visited and recommended to visit. Name of restuarants are: Sisterfield, La Plancha, The Junction Seminyak, Single Fin, Cafe Bali, Betelnut Cafe , Grocer \& Grind, Orchid Tea, Creamy Comfort, 
Shearlock, Angelita Patisserie, LeSica Bali, Expresso Revolver, Bistro Gardens, Livingstone Bakery, Sea Circus, La Laguna, Nook Bali, La Favela, Pomegranate Cafe, The Bistrot and Mexicola Motel.

The influence of the restaurant's physical environment on customer behavior has long been studied by scientists in various countries. In various studies have been tested the influence of physical environmental factors on price perceptions and then influence the perception of prices on the intention of repurchase. The physical environment of the restaurant is the first element that customers will experience after entering a restaurant, forming a key factor for customers. In fact customers want to eat at a restaurant not only for their nutritional needs but also to form a memorable experience, to get along with others and get away from the problems and routines of life. For this reason, the restaurant's physical environment needs to provide elements of interest to customers. The physical environment is an important determinant of consumer psychology and behavior in a restaurant. Satisfied customers will tell their colleagues about their experience so that this can be part of a word of mouth business in the name of the restaurant. Word of mouth promotion has proven to be one of the most effective and trusted forms in a company's marketing efforts. Although difficult to measure, oral recommendations from colleagues undoubtedly have a positive long-term impact on the profitability of a restaurant. So a restaurant is expected to provide the best atmosphere and experience for its customers.

The purpose of this research activity is to know the factors that most influence the customer satisfaction to physical environment at Restaurant in Bali, to know the variables that most influence the customer satisfaction to physical environment at Restaurant in Bali and to know the overall assessment of customer to physical environment of Restaurant in Bali. The benefits of research result is theoretically that in order to know the assessment of customer to physical environment at restaurant in Bali and practically for local government of Bali, as input in developing Bali as world destination, for tourism industry actors, as input in making decision for arrangement of physical environment restaurant in order to compete with its competitors.

\section{LITERATURE REVIEW}

Journal titled: "New or repeat customers: How does the physical environment affect their restaurant experience?" By Ryu K, Han H (2011) examines the conceptual model to examine how customer perceptions of his physical environment are influenced by customer satisfaction, and customer loyalty to restaurants formal. This research uses structural equation model analysis, this research indicates that facility aesthetics, lighting, layout, and service staff have a significant influence on customer satisfaction. Journal entitled: "DINESCAPE: a scale for customers' perception of dining environments" by Ryu K, Jang S (2008) examines the dimensions of the formal restaurant's physical environment to develop the DINESCAPE scale. This study reviews relevant literature, especially environmental and marketing psychology empirically and theoretically. In this study also refine the scale of some items to assess DINESCAPE in a formal restaurant. Based on quantitative analysis, the six factor scale identified in this research is aesthetic of facility, atmosphere, lighting, product service, layout, and social factor. Journal entitled "The EE's Berry LL (2007) examined dining experiences on formal restaurants at least three important factors. Although the quality of the food is very basic, the atmosphere and performance of the service greatly affect the customer ratings for a restaurant. There are several key factors in the assessment of eating experience in a restaurant: functional factors (elements of atmosphere, design and technical) and human factors (elements of performance, behavior, appearance of employees).

Customer perception of function factor have bigger effect than human factor. Although both should always be considered for restaurant managers to maintain the quality of service provided to its customers. Journal entitled: "The Analysis of the Physical Environment Effect on Consumer Buying Interest in Cafes in Surabaya" by Elina, N. et al (0000) examines using questionnaires as a means of data collection. The results showed that facilities aesthetics and table settings have positive and significant impact on consumer buying interest, while ambience, lighting, layout and service staff have positive but not significant effect. The results obtained by aesthetics facilities as the most dominant factor affect consumer 
buying interest. All the above research, can be the basis of consideration in research on the role of the physical environment for customer satisfaction in restaurants in Bali.

Physical environments can also be called an atmosphere, can be more influential than the product itself in determining the purchase. In some cases, the physical environment becomes a major influence for consumers (Ryu, 2015). Ryu (2005) states that the atmosphere is an attempt to design a purchasing environment to create specific emotions that can influence to increase the likelihood of consumers making purchases. In capturing how consumers perceive the physical environment in restaurants, Ryu and Jang (2007) use DINESCAPE. DINESCAPE focuses on the inside of restaurants and does not cover the external environment such as parking spaces and building designs, and does not include inside non-dining areas such as toilets and customer's waiting areas. Ryu and Han (2011) categorizes DINESCAPE into several elements: 1).Facility Aesthetics means all architectural design, interior design and decoration that contribute to the attractiveness of the restaurant's neighborhood. It's important for customers to get the overall color, decor and overall ambience to create a valuable experience for customers. Facility aesthetics includes various furniture, drawings or paintings, plants or flowers, ceiling decorations, and wall decorations can be an important part of marketing tools by influencing customer responses such as attitudes, emotions, perceptions of prices, perceptions of value, consumer satisfaction and behavior (Ryu and Jang, 2007), 2).Ambience is an intangible element as a backdrop that aims to influence the senses in a non-visual way that unconsciously affects the customer. Ambience encompasses the music, aroma and temperature inside the restaurant. Kim and Moon (2009) revealed that ambience has the strongest relationship in consumer perception and has a stronger relationship with the feeling of customer satisfaction, 3).Lighting is the level of consumer comfort will increase with the level of lighting is relatively low. Different types of lighting can affect individual customer perceptions of space and alter customer sensitivity from the physical, psychological and emotional aspects of an area and affect customer buying behavior. According to Hussain and Ali (2015) lighting is aimed at giving a positive effect to products sold by business people. Lighting creates a sense of fun and has a positive impact on customer purchasing behavior, 4).Layout is one of the elements that give pleasure in a middle-up restaurant. Layout refers to the placement of objects such as machines, equipment and furnishings arranged in an environment. Lin (2004) says that the location of a dining table within a restaurant has a profound effect on the overall consumer experience. The placement of the table has the function of providing privacy, describing the desired facilities, and acting as the distance between one customer and another. A good layout will create a positive impression for customers so customers will stay longer and make more purchases (Banat and Wandebori, 2012), 5).Table Setting becomes one of the important physical environment elements in the middle to upper class restaurant. How to design a table by putting flowers or candles as a declaration can also be useful to make customers feel that customers are in a good environment. Table settings can influence cognitive responses (disconfirmation) and affective responses (emotions) customers so that later will affect consumer behavior. Table settings will affect customer behavior (Ryu and Han, 2011), and 6).Service Staff refers to employees within the premises of service. This refers to the employee's appearance, the number of employees, and the employee's gender. Tombs and McColl-Kennedy (2003) argue that service staff are socially related in ways that affect the affective and cognitive responses of consumers and may influence customer buying interest.

\section{MATERIAL \& METHODOLOGY}

This research is a quantitative research, because using statistical analysis that is factor analysis by using Statistical Package for Social Science (SPSS) 19.0 for windows. The choice of the program because there are several facilities analysis one of them is factor analysis. Supranto (2004: 114) mentions that factor analysis is a common name that denotes a class of procedures, primarily used to reduce data or summarize variables that have been changed to a few variables and call it a factor. Simamora (2005: 134) states that the number of extracted factors, can also use the concept criteria concept or a priori, meaning the number of required factors sought based on the concept. In this research with confirmatory factor analysis model that is factor analysis by confirm the factors also sought based on concept of 6 attribute of 
element of restaurant physical environment from Ryu (2005) The location of this research will be conducted at 22 new restaurant in Bali based on field survey data, foodblogger, social media and Trip Advisory in 2017. The location of the restaurant as sample in this research spread in 10 locations in Bali: Seminyak, Pecatu, Canggu, Jimbaran, Kerobokan, Denpasar, Kuta, Mengwi, Ubud, and Petitenget. Of the 10 locations are located in 2 regency and 1 city of Badung, Gianyar and Denpasar. This study was conducted in 3 areas only due to limited time, cost and limitations of researchers.

The type of data in this study used two types of data that is qualitative data and quantitative data. Qualitative data were obtained based on various information from: interviews with owners or restaurant managers, and other data. Quantitative data are data in the form of numbers such as number of new restaurants in Bali, data on respondent characteristics during the study, as well as other data related to the research. While the data source used in this research are: primary data that is, in the form of data obtained directly through research process such as sourced from result of customer questionnaire at 22 restaurant in Bali, result of interview with owner or manager of restaurant and secondary data that is, sourced from Trip Advisor 2017 on new restaurants in Bali, journals on the restaurant's physical environment, as well as some related literature.

Respondents in this study were restaurant customers who had or had visited 22 restaurants during the study period. Sample determination technique used in this research is non-probability sampling with accidental sampling method. Kusmayadi and Sugiarto (2000: 140) explain the sampling using non probability sampling to make a person's chances to become unknown respondents. Accidental sampling techniques are used without careful planning. The respondent asked for the information was actually obtained by chance without any particular consideration. Using this method respondents who respond are determined by chance. For the purposes of data analysis using factor analysis, Supranto (2004: 314) suggests that the sample size (n) in factor analysis is at least 4 (four) or 5 (five) times the number of variables. Based on the consideration of time, cost and data requirement according to factor analysis, the number of samples in this study is determined by 21 variables multiplied by five of 105 respondents. During the period of time the research will be distributed questionnaires to customers in 22 restaurants in Bali from April to July 2017. Research Instruments use variables or indicators that are measured ordinal by using Likert scale. This scale is used to measure attitudes from the most positive level to the most negative level (Kusmayadi and Sugiarto, 2000). In relation to the research of the role of the physical environment on customer satisfaction in restaurants in Bali, respondents should express their views by choosing one of five alternative answers provided, namely: very satisfied given weight5, satisfied given weight 4 , answer quite satisfied given weight 3 , answer not satisfied given weight 2 and answer very dissatisfied given weight 1 Before the research instrument is used to collect the data, then the instrument must be tested with the validity and reliability test. The purpose of the validity and reliability test is to test whether the questionnaire can measure what should be measured and have consistency of results when used by different researchers and respondents. Between (2004) said that the validity and reliability test conducted on at least 30 respondents because with this number the distribution of the score will be close to normal. According to Mantra and Kasto (1989) in the validity test of measuring instrument is valid if the value of correlation coefficient between grains with a total score equal to or more than 0.3 . While the reliability test of an instrument is said to be reliable when the value of Alpha Cronbach coefficient greater 0.6 .

Based on DINESCAPE theory there are 6 dimensions in this research with 21 attributes that exist related to restaurant physical environment. The 6-dimensional distribution with the number of attributes are Facility Aesthetics (5 variables), Ambience (4 variables), Lighting (3 variables), Layout (4 variables), Table Setting (3 variables) and Staff Service (2 variables). The role of the restaurant's physical environment is a construct that is un measureable. The immeasurable factors will be measured ordinal through the Likert scale. Data collection techniques in this study used four ways: observation that is data collection by using participant observation techniques that directly enjoy the service at the restaurant sample research, as well as doing deep observations during the study period, Interviews are data collection by way of question and answer directly by way of interview with parties related to the object of research such as the owner and or restaurant managers during the study period, Questionnaire is Data 
collection by spreading the questionnaire to the respondents are: restaurant customers in Bali during the study period using 2 languages namely Indonesian and English. The questionnaires in this study used a closed questionnaire (fixed alternative question), questionnaires presented in the form of questions that the possible answer has been provided, so that respondents just choose one of the appropriate answers (Kusmayadi, 2000: 88). The form of arrangement using Likert Scale to know the perception of tourists from very dissatisfied until very satisfied associated with the object of research. According to Kusmayadi and Sugiarto (2000: 94) the Likert scale is a tool for measuring positive attitudes and circumstances to a very negative level, to indicate the extent to which approval or disapproval of the statements submitted by the researcher is contained in the questionnaire. The literature is data collection conducted by reading the results of previous research related to the problems studied in several final reports, theses, magazines analysis of tourism, papers and journals about the role of the physical environment of restaurants and reference books, especially the concepts that support and relevant to the problem under study.

Data analysis using factor analysis to answer the purpose of this study is to determine the factors and variables that most play a role in knowing the perception of restaurant customers related to the role of physical environment in restaurants in Bali. According to Santoso and Tjiptono (2001), the first factor analysis stage by formulating the problem, second by making a correlation matrix, the third determining the number of factors, the fourth rotating factor, the fifth determining the model accuracy and the six interpretations Factor.

\section{RESULT AND DISCUSSION}

\section{A. Test Validity and Reliability.}

Validity is an index indicating the extent to which a measuring instrument can be trusted or reliable (Wardiyanta, 2006: 24). If the value of $\mathrm{Ri}>0.3$, then the instrument can be declared valid and can be used in further research. Result of validity test of question which used in this research is complete can be seen in appendix. Testing of this validity using 30 respondents researched $(\mathrm{N}=30)$. The results of validity test in this study shows the interval of 0.313 to 0.614 which means that the research instrument has fulfilled the validity requirement with the total item-total correlation coefficient of each greater than $0.03(\mathrm{Ri}>$ $0.3)$. Thus a feasible or valid research instrument is used as a data collector. Reliability is an index that indicates the extent to which a measuring instrument can be trusted or reliable to retrieve data. Sugiyono (2003) argues that the instrument is said to be reliable if the instrument is used multiple times to measure the same object is able to produce relatively similar data. Therefore, reliability testing of the measuring instrument is intended to indicate the extent to which measuring instruments are reliable or reliable in data retrieval. The reliability test was performed by alpha-Cronbanch variance test. If the alpha-Cronbach ri value> 0.6; then the instrument is declared valid and can be used in research. The result of instrument reliability test in this research, alpha coefficient 0,765 as shown in appendix. With a value of alphacronbach $0.765>0.6$ so that the instrument of this study can be trusted, reliable and accurate as a data collector.

\section{B. Characteristics of Respondents.}

This study used the opinions of the customers who had and had visited 22 restaurants where the research during the study period (April-July 2017). The importance of the description of the characteristics of respondents because many aspects that influence the customer satisfaction of the physical environment of restaurants in Bali. Characteristic analysis of this respondent consist of: country of origin, sex, age, occupation, information about restaurant and visit frequency. From the results of research, the characteristics of customers who came to 22 restaurants in Bali in the study period are as follows: a). Country of origin: overseas customers (Asia, Europe, Australia, America) 60\%, domestic customers (Jakarta, Surabaya, Yogyakarta, Balikpapan, Papua) 40\%. b). Gender: female (60\%) and male (40\%), c). Age of tourists: between 15 years to 50 years, d). Employment: Employee (35\%), Entrepreneur (30\%), Corporate Leader (15\%), Student (10\%), Student (10\%), e). Information about restaurants: Friends (40\%), social media (40\%), family (20\%), f). Visit frequencies: 2 times (50\%), 3 times (40\%), more than 3 times $(10 \%)$ 


\section{Factor Analysis}

Often factor analysis is a preliminary analysis of a problem in research, namely in an attempt to get a new variable or latent variable that present some items or dimensions that are observed variable or observed variable. From latent variables or factors formed must be new data, which is a factor score value (SF), which is used as the basis of further analysis. The score value of the latent variable factor that is formed depends on the item or the dimension of the constituent (Solimun, 2002). In this research, there are partial factor analysis in which each analysis uses factor confirmation analysis from the constituent items of each factor that is as much as six factors. Then the 6 (six) factors are coded as follows: 1). F1Facility Aesthetics / Facility Aesthetics, 2). F2- Atmosphere / Ambience, 3). F3 - Lighting / Lighting, 4). F4- Layout / Layout, 5). F5 - Table Setting, and 6) F6 - Service Staff / Service Staff While the 21 variable form factor is also given the code as follows: X1. Clean furniture, X2. Interesting colors, X3. Quality furniture, X4. Attractive paintings / photos, X5. The wall decor is interesting, X6. Comfortable room temperature, X7. A pleasant aroma, X8. Background music, X9. Voice background, X10. Comfortable lighting, X11. Effect of mosional lighting, X12. Warm lighting, X13. Comfortable seating arrangement, X14. Custom layout, X15. Size and shape of layout, X16. Planning a layout sufficient to move comfortably, X17. Quality of cutlery, X18. Options near the window, X19. Linen is interesting, X20. Tidy clothing and employee uniforms, X21. The number of employees is adequate. By looking at the observed variables can be formed the factors in accordance with the grouping based on confirmatory factor analysis that is the factor has been determined its constituent components (Xi). So the value of the factor score is determined by the component of the constituent component of the factor.

\section{Facility Aesthetics Factor Analysis (F1)}

The result of facility aesthetic factor analysis (F1) is the result of joint analysis (factor score $=$ FS) of five observed variables: X1. Clean furniture, X2. Interesting colors, X3. Quality furniture, X4. Attractive paintings / photos, X5. The wall decor is interesting. After processing the data for the aesthetic factor of the facility (F1), as can be seen in the attachment, obtained KMO value of 0.560 this means KMO> 0.5 and with the value of Sig $<0,000$ which means all observed variables are feasible to be factored (Tenaya, 2002 ). However, when viewed the correlation anti-image X1 to X5, there is one correlation anti-image value: $\mathrm{X} 4$. The attractive painting / photograph smaller than 0.5 is 0.458 , so the $\mathrm{X} 4$ variable must be removed from the facility's aesthetic factor (F1), and must be re-invoked without the $\mathrm{X} 4$ variable. After elimination of variable X4. Paintings / photos are attractive, then the results of the KMO test and its communality can be seen that the result of factor analysis of the five variables that play a role on the aesthetic factor of the facility (F1) is valid for factored with a KMO value of 0.574 greater than 0.05 and a significance value (Sig.) Of 0.000 is smaller 0.05; so it can be said that X4. Attractive paintings / photos do not play a role in the establishment of the facility's aesthetic factor (F1).

The role of each variable on the factors formed can be known from the value of communality. The result of KMO test and communal of facility aesthetic factor (F1) which states percentage of each factor variable in forming facility aesthetic factor (F1) which can be explained by factors formed, such as variable X1 (furniture clean) equal to $69,2 \%$; variable X2 (color of interest) equal to $61,2 \%$; X3 variable (quality furniture) equal to $35,2 \%$ and variable X5 (wall decoration of interest) equal to $35,2 \%$. It turns out that X1 (clean furniture) has the highest role in the formation of facility aesthetic factor (F1), followed by $\mathrm{X} 2$ variable (attractive color) and the smallest one is X3 (quality furniture) and X5 (attractive wall decoration). The eigenvalue and matrix components of the facility's aesthetic factor (F1) state that the aesthetic factor of the facility (F1) can represent its forming component of $60.680 \%$ of the total variance, which means that one factor represents the four variables X1, X2, X3, X5 with value the initial eigenvalue of 1,400 are greater than 1.00. Then the results of matrix component analysis, which shows the closeness of correlation or correlation of each variable from X1 to X5 which make up the aesthetic factor of facility (F1). The higher the value of the matrix component of each variable, the stronger the relationship of the variable or the greater the role in the formation of factors. It can be seen that the variable X1 (clean furniture) has the strongest relationship to the aesthetic factor of the facility (F1) with the correlation coefficient of 0.832 , followed by the variable X2 (attractive color) with a correlation coefficient of 0.782 ; 
and the weakest is the X3 (quality furniture) and X5 (attractive wall decorations) with a correlation coefficient of 0.594 .

\section{E. Atmosphere Factor Analysis (F2)}

Result of atmosphere factor analysis (F2) is result of joint analysis (factor score) from four variable that is X6. Comfortable room temperature, X7. A pleasant aroma, X8. Background music, and X9. Sound background. After doing data processing got value of KMO equal to 0,546 this mean KMO> 0,5 and with value of Sig $<0,000$ which mean all observed variable feasible to factored. So with a KMO value of 0.546 as shown it shows that the correlation between pairs of factor-forming variables can be explained by other variables and appropriate factor analysis is performed. And if we see the anti-image correlation X6 sd X9 as in the attachment, the value is all already greater than 0.5 .

The role of each variable on the factors formed can be known from the value of communality. The result of KMO test and atmosphere factor communiqués (F2) which states the percentage of each factor variable in forming atmosphere factor (F2) that can be explained by the factors formed, such as X6 variable (comfortable room temperature) equal to $74.7 \%$; variable $\mathrm{X} 7$ (pleasant aroma) equal to $59,5 \%$; variable X8 (music background) of $36.0 \%$; variable X9 (sound background) of $7.8 \%$. It turns out that variable X5 (comfortable room temperature) has the highest role in the formation of atmosphere factor (F2), followed by X7 variable (pleasant aroma); and the smallest of the four variables X9 (sound background). The eigenvalues and matrix components of the atmosphere factor (F2) state that the atmosphere factor (F2) can represent the forming component of $60,500 \%$ of the total variance, which means that one factor represents the four variables X6 to X9 with the initial eigenvalues, of 1.780 is greater than 1.00. The results of matrix component analysis the correlation relationship or correlation of each variable from X6 to X9 which make up the atmosphere factor (F2). The higher the value of the matrix component of each variable, the stronger the relationship of the variable or the greater the role in the formation of factors, and vice versa. It can be seen that the X6 variable (comfortable room temperature) has the strongest relationship to the atmosphere factor (F2) with the correlation coefficient of 0.864 , followed by the variable X7 (pleasant aroma) with a correlation coefficient of 0.771 ; and the weakest is the X8 variable (sound background) with a correlation coefficient of 0.280.

\section{F. Lighting Factor / Lighting (F3)}

The result of lighting factor analysis (F3) is the result of joint analysis (factor score $=$ FS) from three observed variables that is X10. Comfortable lighting, X11. Effects of mosional lighting, and X12. Warm lighting. After doing the data processing got the value of KMO of 0.475 is smaller than 0.5 (KMO value> $0.5)$ although with the value of $\mathrm{Sig}<0.423$ which means that all observed variables not feasible to factored. So with the value of KMO 0.475 as shown in the attachment, shows that the correlation between pairs of variable-forming factors can not be explained by other variables and factor analysis has not been done. So to make the lighting factor (F3) is valid for the factored, we will look for and exclude one lighting factor-forming variable that has the lowest correlation anti-image value. X12 (warm lighting) has the smallest anti-image value, so this X12 variable must be removed from the lighting factor (F3), then it must be re-done without the X12 variable. After elimination of X12, the result of KMO test and the factor of enrichment community (F3). It can be seen that the result of factor analysis of two variables that play a role on the lighting factor $(\mathrm{F} 3)$ is valid to be factored with a KMO value of 0,500 (requirement of KMO value equal to or> 0.5) and significance value (Sig.) Of 0,000; so it can be said that the variable X12 does not play a role in the formation of the lighting factor (F3).

The role of each variable on the factors formed can be known from the value of communality. The result of KMO test and the lighting factor (F3) which states the percentage of each factor variable in the forming of the lighting factor (F3) which can be explained by the factors formed, such as X10 (comfortable lighting) variable is 54.2\%; and variable X11 (precision of emotional effect of enrichment) also equal to $54,2 \%$. From these results the two variables are X10 and X11 have the same role in the formation of lighting factor (F3). The eigenvalue and the exposure factor matrix (F3) states that the illumination factor F3 represents the composition component of $64.160 \%$ of the total variance, which means that one factor represents the three variables X10 and X11, with an initial eigenvalues value, of 
1.083 is greater than 1.00. The results of matrix component analysis such as Table 4.6, which shows the closeness of the correlation or correlation of each variable of X10 and X11 that make up the lighting factor (F3). The higher the value of the matrix component of each variable, the stronger the relationship of the variable or the greater the role in the formation of factors. It can be seen that the X10 variable (comfortable lighting) has a strong relationship with the X11 variable (Lighting emotional effect) on the illumination factor (F3) with the correlation coefficient of 0.736 .

\section{G. Layout Factor Analysis / Layout (F4)}

The result of layout factor analysis (F4) is the result of joint analysis (factor score $=$ FS) from four observed variable that is X13. Comfortable seating arrangement, X14. Custom layout, X15. The size and shape of the layout, and X16. Planning a layout sufficient to move comfortably. After processing the data for the layout factor F4, as can be seen in the attachment, obtained KMO value of 0.638 means KMO> 0.5 and with the value of Sig $<0,000$ which means that all observed variables deserve to be factored (Tenaya, 2002 ). So with a value of $0.638 \mathrm{KMO}$. It shows that the correlation between pairs of factor-forming variables can be explained by other variables and appropriate factor analysis is performed. And if we see the anti-image correlation value X13 to X16 as in the attachment, its value is all greater than 0.5.

The role of each variable on the factors formed can be known from the value of communality. The result of KMO and communicability of layout factor $(\mathrm{F} 4)$ which states the percentage of each factor variable in forming layout factor (F4) which can be explained by the factors formed, such as X14 (comfortable seating arrangement) is 57, 3\%; variable X15 (special layout) of 64.4\%; variable X15 (size and shape of the layout) and X16 (layout planning enough to move comfortably) the same that is equal to $52.00 \%$. It turns out that X15 (special layout) has the highest role in the formation of layout factor (F4), followed by X14 variable (comfortable seating arrangement) and the smallest of the four variables X15 (size and shape of layout) and X16 (layout planning enough to move comfortably). The eigenvalues and layout matrix factor (F4) states that the layout factor F4 represents the forming component of $60.920 \%$ of the total variance, which means that one factor represents the four variables X13 / X16 with the root value (initial eigenvalues) of 1.737 is greater than 1.00 .

Then the results of matrix component analysis, which shows the closeness of the correlation or correlation of each variable from X13 to X16 which construct the layout factor (F4). The higher the value of the matrix component of each variable, the stronger the relationship of the variable or the greater the role in the formation of factors, and vice versa. From table 4.8 it can be seen that X13 variable (comfortable seating arrangement) has the strongest relationship to layout factor (F4) with correlation coefficient of 0.802 , followed by employee variable X14 (special layout) with correlation coefficient 0,757; and X15 variable (size and shape of the layout) and X16 (layout planning enough to move comfortably) with a correlation coefficient of 0.721

\section{H. Analysis of Guest Setting Factor / Table Setting (F5)}

The result of the analysis of table feeding factor (F5) is the result of joint analysis (factor score $=$ FS) of three observed variables: X17. Quality of cutlery, X18. Options near the window, X19. The linens were interesting. After processing the data for table feeding factor (F5), as can be seen in the attachment, obtained KMO value of 0.658 means $\mathrm{KMO}>0.5$ and with $\mathrm{Sig}<0,000$ which means all observed variables are feasible to be factored (Tenaya, 2002). So with a KMO value of 0.658. It shows that the correlation between pairs of factor-forming variables can be explained by other variables and appropriate factor analysis is performed. And if it is seen that the anti-image correlation X17 sd X19 as in the attachment, its value is all greater than 0.5 .

The role of each variable on the factors formed can be known from the value of communality. The result of KMO test and table feeding factor communiquity (F5) which states the percentage of each variable factor in the form factor of table setting (F5) which can be explained by the factors formed, such as X17 variable (quality of cutlery) $68,4 \%$; variable X18 (choice near the window) of $64.0 \%$; and X19 (interesting linen) equal to $62.00 \%$. It turns out that X17 (the quality of cutlery) has the highest role in the formation of table feeding factor (F5), followed by X18 variable (choice near the window) and the 
smallest of the three variables X19 (interesting linen) Eigenvalue value and matrix components of table feeding factor (F5) states that table feeding factor (F5) can represent the forming component of $60.820 \%$ of the total variance, which means that formed one factor representing three variables that is X17 s / d X19 with value the initial eigenvalues of 1.730 are greater than 1.00 . Then the results of matrix component analysis which shows the closeness of correlation or correlation of each variable from X17 to X19 which make up the table feeding factor (F5). The higher the value of the matrix component of each variable, the stronger the relationship of the variable or the greater the role in the formation of factors. It can be seen that the X17 variable (quality of guest eating utensil) has the strongest correlation to guest table arrangement factor (F5) with correlation coefficient of 0.815 , followed by employee X18 variable (choice near window) with correlation coefficient 0,756 ; and the weakest relationship is variable X19 (interesting linen) with a correlation coefficient of 0.721.

\section{Employee Factor Analysis Service / Service Staff (F6)}

The result of factor service employee analysis (F6) is the result of joint analysis (factor score $=$ FS) of two observed variables X20 (tidiness of clothing and uniforms of employee interest) and X21 (sufficient number of employees). After processing data for service employee factor (F6), as can be seen in appendix, got $\mathrm{KMO}$ value equal to 0,602 this mean $\mathrm{KMO}>0,5$ and with value of Sig <0,000 which means all observed variable is feasible to factored (Tenaya, 2002 ). So with a value of $0.602 \mathrm{KMO}$ as shown in Table 4.7, shows that the correlation between pairs of factor-forming variables can be explained by other variables and appropriate factor analysis is performed. And if we see the anti-image correlation value X20 and $\mathrm{X} 21$ as in the attachment, its value is all greater than 0.5 .

The role of each variable on the factors formed can be known from the value of communality. The results of the KMO test and the factor communication of the Employee Service (F6) state the percentage of the roles of each factor constituent variable in the shaping factor of service employees (F6) that can be explained by the factors formed, such as X20 variables (tidiness of clothing and uniforms of employee interest) of $58,5 \%$; and variable X21 (adequate number of employees) of 64.5\%. It turns out that X21 (adequate number of employees) has the highest role in the formation of service employee factors (F6), followed by X20 variables (tidiness of clothing and uniforms of employee interest). The Eigenvalue and Service Service matrix matrix (F6) states that the service employee factor (F6) can represent the forming component of $60.820 \%$ of the total variance, which means that one factor represents the two variables X20 and X21 with the initial root value eigenvalues) of 1.745 is greater than 1.00 . Then the matrix component analysis results, which shows the closeness of the correlation or correlation of each variable of X20 and X21 that make up the employee service factor (F6). The higher the value of the matrix component of each variable, the stronger the relationship of the variable or the greater the role in the formation of factors. It can be seen that the variable X21 (adequate number of employees) has the strongest relationship to service employee factor (F6) with correlation coefficient of 0.645 , followed by X20 employee variable (tidiness of clothing and uniforms of employee interest) with correlation coefficient of 0.585 .

\section{J. Analysis of Customer Satisfaction}

From the above factor analysis, it can be seen that from each factor has the most powerful or decisive variable for the factor that is: 1). Facility Aesthetic Factor (F1) with variable X1 (clean furniture) with correlation coefficient of $0.832,2$ ). Factor Atmosphere $(\mathrm{F} 2)$ with variable X6 (comfortable room temperature) with coefficient correlation $0.864,3)$. Lighting Factor (F3) with X10 variable (convenient lighting) and X11 variable (emotional effect of illumination) with correlation coefficient $0.736,4$ ). Layout Factor (F4) with X13 variable (comfortable seating arrangement) with coefficient correlation 0.802, 5). Guest Table Setup Factor (F5) with X17 variable (quality of guest dining equipment) with correlation coefficient of 0.815 and 6). Employee Service Factor (F6) with variable X21 (number of employees adequate) with the correlation coefficient sebasar 0.645 . Based on the purpose of this study, and the results of the above analysis can be concluded that the X6 variable (comfortable room temperature) has the strongest role in forming atmosphere factor $(\mathrm{F} 2)$ with the correlation coefficient 0.864 , followed by $\mathrm{X} 1$ (clean furniture) aesthetic facility (F1) with correlation coefficient of 0.832 . 
The interpretation for: 1). the facility's aesthetic factor analysis (F1) that the restaurant customers when they enjoy their dining experience at a restaurant in Bali is concerned with clean furniture compared to attractive colors, quality furniture and attractive wall decorations. The results of interviews with the owners or managers in the restaurant get the result that if the furniture is dirty, guests will not feel comfortable then very easily they will complain or they will go especially in the hours that are very busy or busy. So that the cleanliness of the furniture as part of the aesthetic facilities will get a considerable portion of attention to be maintained by the quality of the restaurant, 2). the atmosphere factor analysis (F2) that restaurant customers as they enjoy their dining experience at a restaurant in Bali is concerned with a comfortable restaurant room temperature rather than a pleasant aroma, or background music or sound background. The results of interviews with owners or managers of the restaurant stated that they are very maintaining the temperature or room temperature so that their customers are comfortable while enjoying their eating experience. If the restaurant has outdoor (outdoor) or smoking area facilities, they will ensure a comfortable air circulation for their customers, 3). the lighting factor analysis (F3) that restaurant customers as they enjoy their dining experience at a restaurant in Bali is concerned with comfortable lighting including the emotional effects that result from existing lighting. Interviews with the owners and managers of the restaurant that the lighting is very supportive than the atmosphere effects will be generated, especially during dinner time, 4). the layout factor analysis (F4) that restaurant customers as they enjoy their dining experiences at a restaurant in Bali is particularly concerned with comfortable seating arrangements rather than special layouts, layout sizes and layouts, and layout planning sufficient to move with comfortable. The results of interviews with owners and managers of the restaurant that now many reasons their customers come to the restaurant because they want to gather with family, colleagues and friends. Comfortable seating arrangements enable restaurant customers to have both privacy and also comfortable mobility of motion. No doubt the photo activity together and also the selfie looking for interesting events to do when hanging out. Therefore, restaurant managers will focus more on the seating arrangements of customers to be more comfortable for them, 5). the analysis of guest table arrangement (F5) that restaurant customers as they enjoy their dining experience at a restaurant in Bali is particularly concerned with the quality of guest dining equipment rather than near-window choices or the availability of attractive linens. The results of interviews with the owners and managers of the restaurant stated that with quality dining equipment the guests will be more satisfied, especially if the equipment is in accordance with the function and design to follow the development of the era or trend of contemporary, 6). the employees' service analysis (F6) that restaurant customers as they enjoy their dining experience at a restaurant in Bali is concerned with an adequate number of employees rather than the neat tidiness of clothing and employee uniforms. Interviews with restaurant owners and managers suggest that the adequacy of employees who will provide services to customers at restaurants is more important in maintaining customer satisfaction in restaurants. Satisfactory customer satisfaction at 22 new restaurants in Bali to the physical environment of the restaurant gave very satisfied input (55\%), followed by satisfied $(35 \%)$ and neutral $(10 \%)$ of overall general rating by 117 restaurant customers. This indicates that the customers are very concerned about the atmosphere of a safe and comfortable restaurant when they enjoy their eating experience. In general, customers also suggest the restaurant provides Wi-Fi or internet connection for free for its customers as an effort in providing satisfaction for its customers.

\section{CONCLUSION}

From the results of the discussion in the previous chapter obtained results: 1). The most determining factor of customer satisfaction in restaurant in Bali to its physical environment is atmosphere factor (F2) followed by facility aesthetic factor (F1), 2). Variable that most determine the satisfaction of customers in restaurants in Bali to the physical environment is variable X6 comfortable room temperature followed by variable $\mathrm{X} 1$ is clean furniture. 3). In general, customers at new restaurants in Bali expressed satisfaction with the physical environment of the restaurant where they enjoyed their eating experience.

The results of this study can be useful for restaurant management in Bali, for the government and for other researchers. For the restaurant management in Bali should be able to improve the factors that have 
not been good and maintain the already good factors, especially the physical environment of the restaurant. For the government to pay more attention to the quality of products and infrastructure facilities in restaurants in Bali to be able to maintain customer satisfaction. For other researchers, for this research can be forwarded especially more broadly with the same field of customer satisfaction in restaurants in Bali.

\section{REFERENCES}

Banat, A. \& Wandebori, H.S.T (2012). Store design and store atmosphere effect on customer sales per visit economics. 2nd International Conference on Business. Economics, Management and Behavioral Sciences. Retrieved March 16, 2016

Elina, N. Dkk (2016) Analisa pengaruh physical environment terhadap minat beli konsumen di kafe-kafe di Surabaya. Manajemen Perhotelan, Universitas Kristen Petra, Surabaya, Indonesia. Journal Petra, 411-423

Hussain,R.\& Ali, M (2015). Effect of store atmosphere on customer purchase intention. International Journal of Marketing Studies, 7 (2), 35-43

Kim, W.G. \& Moon Y.J (2009). Customers cognitive, emotional and actionable response to the servicescape : A test of the moderating effect of the restaurant type. International Journal of Hospitality Management, 28 (1), 144-156

Lin, I.Y (2004). Evaluating a servicescape: The effect of cognitiion and emotion. International Journal of Hospitality Management, 23 (2), 163-178

Ryu, K (2005). DINESCAPE, emotions and behavioral intentions in upscale restaurants. Doctoral dissertation. Retrived April 21. 2016, from Kansas State University.

Ryu, K and Jang, S,C (2007). The effect of environmental perceptions on bevavioral intentions through emotions: The case of upscale restaurant. Journal of Hospitality \& Tourism Research, 31 (1). 5672

Ryu K, Jang S (2008a) DINESCAPE: a scale for customers' perception of dining environments. Journal of Foodservice Business Research11: 2-22.

Ryu K, Han H (2011) New or repeat customers: How does physical environment influence their restaurant experience?. International Journal Hospitality Management, 30 (3): 599-611.

Tomb, A. \& McColl-Kennedy, J.R (2003). Social-servicescape conceptual model. Marketing Theory, 3 (4), 447-475

Tusukan, et.al. 2016. The Important of Restaurant Physical Environment For Turkish Customers. J Tourism Res Hospitality . Journal of Tourism. Research and Hospitality. Turkey

Wall EA, Berry LL (2007) The combined effects of the physical environment and employee behavior on customer perception of restaurant service quality.Cornell Hotel RestaurAdm Q 48: 59-69.

Tenaya, IM. Narka.2002. Kuantivikasi data Kualitatif dengan metode MSI (Metode Suksesif IntervalMSI) Laboratorium Statistika. Fakultas Pertanian. Universitas Udayana

Kusmayadi dan Sugiarto, Endar. 2000. Metode Penelitian dalam Bidang Kepariwisataan. Jakarta: PT. Gramedia Pustaka Utama.

Mantra,IB, dan Kasto. 1989. Penentuan Sampel dalam Metode Penelitian Survai, Editor Masri Singarimbun dan Sofian Effendi. Jakarta: LP3ES

Simamora, Bilson.2005. Analisis Multivariat Pemasaran. Jakarta: PT Gramedia Pustaka Utama

Supranto, J. 2004. Pengukuran Tingkat Kepuasan Pelanggan Untuk Menaikkan Pangsa Pasar. Jakarta: Rineka Cipta 